\title{
Çizgili İshakkuşu Otus brucei (Hume 1872) Peletlerindeki Küçük Memeli Hayvan Kalıntıları
}

\author{
Alaettin KAYA ${ }^{1}$, Seven SEÇKİN ${ }^{2}$, Mustafa KOÇKAYA ${ }^{3}$, Işıl COŞKUN MUSAOĞLU ${ }^{4}$, \\ Yüksel COŞKUN ${ }^{1 *}$ \\ ${ }^{1}$ Dicle Üniversitesi Fen Fakültesi Biyoloji Bölümü, Diyarbakır \\ ${ }^{2}$ Dicle Üniversitesi Fen Bilimleri Enstitüsü Biyoloji Bölümü, Diyarbakır \\ ${ }^{3}$ Cumhuriyet Üniversitesi Veteriner Fakültesi Temel Bilimler, Sivas \\ ${ }^{4}$ Şanlıurfa Birecik Devlet Hastanesi, Şanliurfa
}

\begin{abstract}
$\ddot{O} \mathbf{z}$
Güneydoğu Anadolu, Şanlıurfa Birecik'ten toplanmış, Çizgili İshakkuşu (Otus brucei)'na ait 26 pelet içerisinde 31 memeli hayvan kalıntısı incelenmiştir. İki memeli ordosuna ait beş türe (Soricomorpha: Crocidura suaveolens, ve Rodentia: Microtus guentheri, Mus sp., Meriones tristrami, Cricetulus migratorius) ait kalıntılar tespit edilmiştir. Her pelette ortalama 1,85 memeli hayvan kalıntısı bulunmuştur. Pellet içinde tespit edilen memeli kalıntılarını \% 87,1 oranında kemirgenler oluştururken \%12,9'unu böcekçil memeli kalıntıları meydana getirmektedir. Ev faresi Mus sp, ve Cricetulus migratorius'un, kalıntılar içerisinde aynı oranda \%29,03 ile en bol bulunan türler oldukları tespit edilmiştir.
\end{abstract}

Anahtar kelimeler: Otus brucei, Rodentia, Memeliler, Çizgili İshakkuşu, Pelet, Türkiye.

\section{Small Mammal Remains in Pallid Scops Owl Otus brucei (Hume 1872) Pellets}

\begin{abstract}
Pellets, regurgitated by the Pallid Scops Owl (Otus brucei), were collected from Şanllurfa-Birecik in southeastern Anatolia. In 26 pellets analyses yielded remains of 31 individuals, representing two mammalian order (Soricomorpha: Crocidura suaveolens, and Rodentia: Microtus guentheri, Mus sp., Meriones tristrami, Cricetulus migratorius). The number of prey items per one pellet ranged from 1-3 individuals (Average 1.85 skull). Rodens constituted $87,1 \%$ of its diet, while Soricomorpha constituted $12.9 \%$. The House Mouse Mus sp., and Cricetulus migratorius, were the most abundant prey items, representing $29.03 \%$ of the total number of recovered prey items.
\end{abstract}

Keywords: Otus brucei, Rodentia, Mammals, Pallid Scops Owl, Pellets, Turkey.

\section{Giriş}

Çizgili İshakkuşu, (Otus brucei), baykuşgiller familyasına ait küçük kulaklı bir baykuş türüdür. İshak kuşuna görünüşte benzer olup vücudunun arka tarafinda şeritler ve daha az karmaşık renkte tüyler görülür [1]. Gövdesi açık gri, yüzü daha açık renklidir. Alt tarafındaki çizgiler daha kalın ve düzenlidir (Şekil 1). Otus brucei Ortadoğu (Türkiye'nin güneyi, Misır, Suriye, Irak, Ürdün, Arabistan'ın doğusu)'dan Afganistan, Pakistan, Orta Asya ve Hindistan'a kadar uzanan bölgede parçalı dağılım gösterir [2]. Bu baykuş türünün Türkiye'deki bilinen dağılımı Aşağı Fırat'la sınırlı, yarı çöl alanlardır $[1,3]$.

\footnotetext{
* Sorumlu yazar: yukselc@dicle.edu.tr

Geliş Tarihi: 14/02/2018 Kabul Tarihi: 23/03/2018
} 


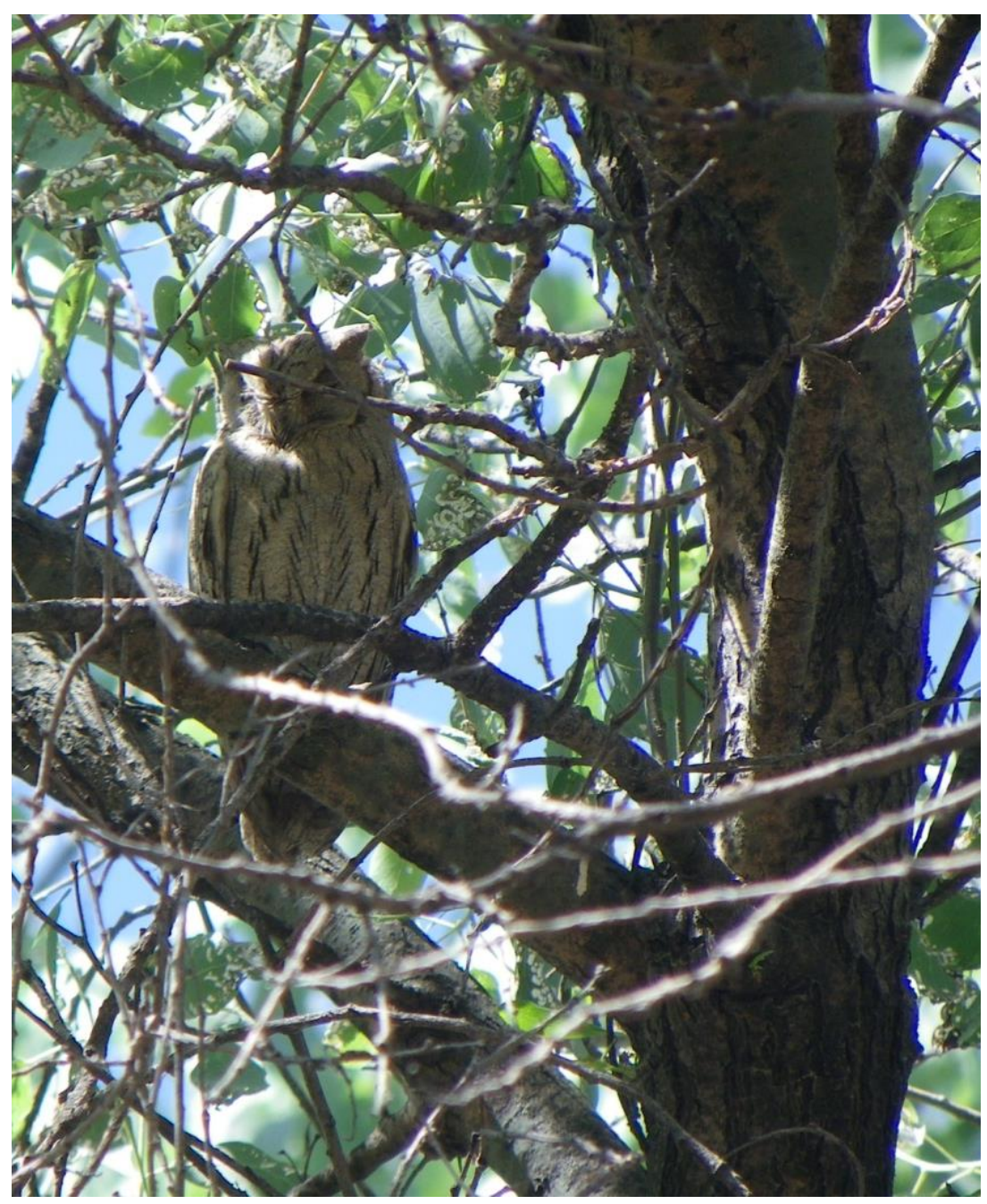

Şekil 1. Şanlıurfa- Birecik Söğütlü Parkta tüneyen bir Çizgili İshakkuşu (Otus brucei) (Foto. A. Kaya, 2016)

Baykuşlar besinlerini (küçük memeli hayvanlar, böcekler, kuşlar, vb.) ya bütün olarak ya da iri parçalar halinde yutarlar. Yuttukları bu besinlerin içerisindeki kafatası, diş, kemik, tüy ve post gibi sindirilemeyen kısımları tünedikleri alanlara kusarak çıkarırlar. Çoğunlukla gri renkli olan bu kusmuk topları pelet olarak isimlendirilir (Şekil 2).

Baykuş peleti analiz çalışmaları, bir bölgedeki küçük memeli hayvan faunasının tespitinde (türlere zarar vermeden ve tuzakla yakalamaya gerek kalmadan) ve baykuşların besin tercihlerinin belirlenmesinde kullanılan hızlı, ucuz ve kolay bir yöntemdir. Pek çok ülkede, bir bölgede yaşayan memeli hayvan türlerinin ve yoğunluklarının belirlenmesinde ve bölgenin ekolojik özellikleri hakkında fikir edinmede bu yöntem yaygın olarak kullanılmaktadır [4-7].

Son yıllarda benzer baykuş peleti analiz çalışmaları yoğun olarak Türkiye'de de yapılmaktadır [8-11]. Steiner ve Vauk [12] Beyşehir Gölü çevresinden; Seçkin ve Coşkun [13-14] Diyarbakır'dan; Turan [15] ve Bulut ve ark. [16] Ankara- Beytepe'den; Hızal [17] Konya- Karapınar'dan; Göçer [18] Denizli'den; Kaya ve Coşkun [19] Erzurum'dan ve Selçuk ve ark [20] Amasya'dan Asio otus (Kulaklı Orman Baykuşu); Hoppe [21] Antakya-Samandağ; Seçkin ve ark [22] Diyarbakır çevresinden Tyto alba (Peçeli Baykuş); Morgan [23] Bitlis'ten ve Seçkin ve ark. [24] Diyarbakır Bismil'den Bubo bubo (Puhu) ile Kaya ve Coşkun [25] Nevşehir'den Athene noctua (Kukumav), Tyto alba ve Bubo bubo türlerinin peletlerini inceleyerek yöredeki küçük memeli hayvan türlerine ait kalıntılar tespit etmişlerdir. 
Bu çalışmada Çizgili İshakkuşu (Otus brucei) peletlerinin analizi ile Şanlıurfa-Birecik’te bu türün beslenmesinde önem arz eden memeli türleri belirlenmeye çalışılmıştır.

\section{Materyal ve Metot}

Çizgili İshakkuşu (Otus brucei)'nun 26 pelet örneği, Şanlıurfa İl Çevre ve Orman Müdürlügü Birecik Fidanlık Mühendisliği (Orman Tarım İşleri Müdürlüğü) içindeki ağaç diplerinden toplanmıştır. Peletlerin toplandığı alanda, kısa boylu çalılık araziler, küçük ağaçların meydana getirdiği çamlık alan, fidan yetiştirilen bölgeler ve büyük boylu servi ağaçları bulunmaktadır.

Ornitologlar [3] Türkiye'nin güneyinde, Suriye ve Irak'1n kuzeyinde, Özbekistan ve Kuzey Afganistan'da Otus brucei obsoletus alttürünün dağılış gösterdiğini belirtmektedirler. Dolayısıyla Şanlıurfa-Birecik'te toplanmış olan peletlerin bu alttüre ait olabilecekleri söylenebilir.

Peletler 2007 yılının Nisan ayında toplanmış olup Dicle Üniversitesi Fen Fakültesi Biyoloji Bölümünde korunmaktadır (Şekil 2).

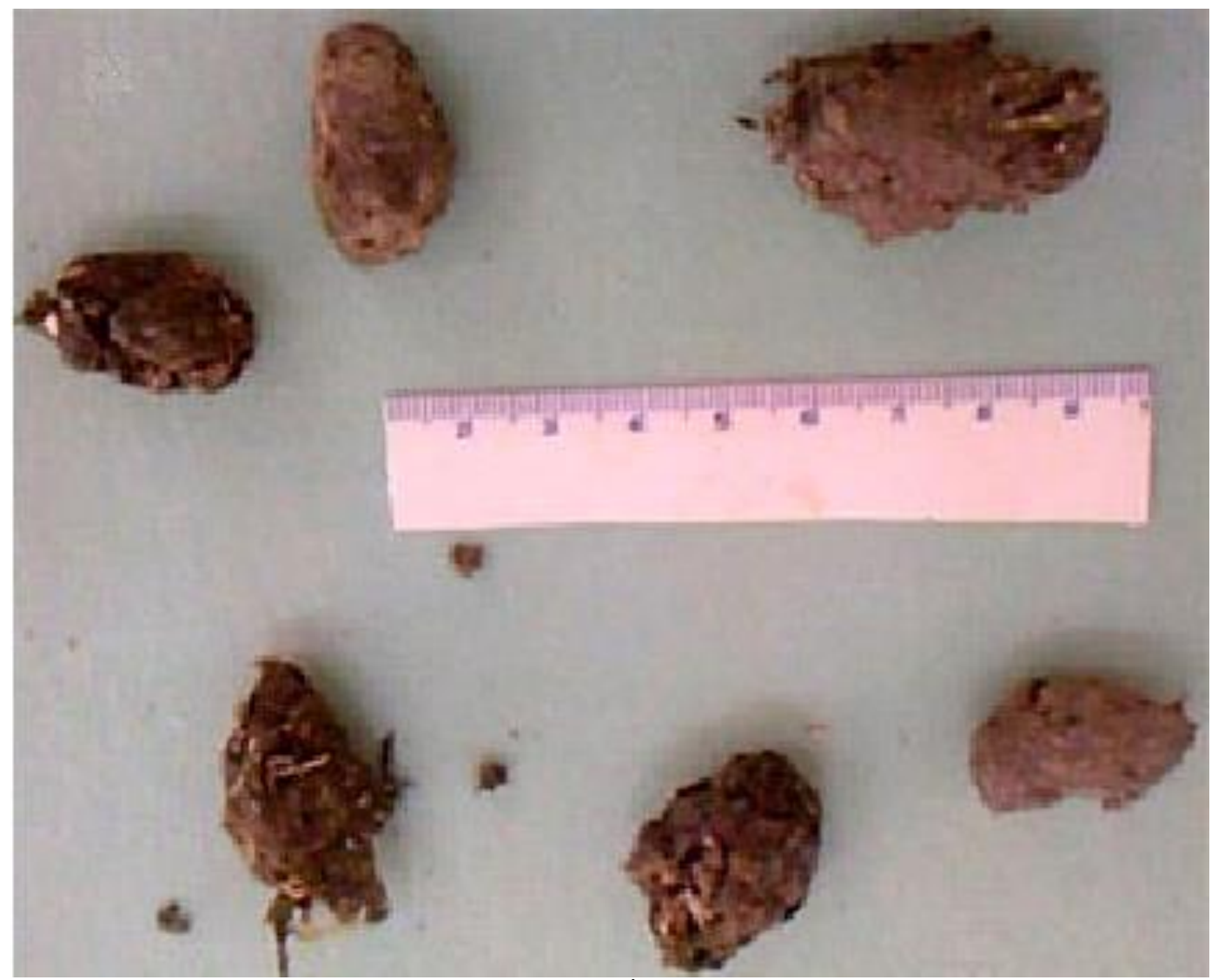

Şekil 2. Şanlıurfa- Birecik Çizgili İshakkuşu (Otus brucei) peletleri.

Pelet içerikleri Obuch [26]; Amr ve ark., [6]'nın kullandıkları yöntemlere uygun olarak incelenmiştir. Alkol içerisinde birkaç dakika sterilize edilen peletler su içine alınarak yumuşaması sağlanmış ve pelet içerisindeki kalıntıların iğne ve pens yardımı ile tasnifleri yapılarak (kafatası, alt çene ve diğer kemikler) analiz için ayrı kutulara alınmıştır. Kalıntıların teşhisi için çeşitli tür tayin anahtarları kullanılmıştır [27$35]$. 


\section{Bulgular ve Tartışma}

Çizgili İshakkuşu (Otus brucei)'na ait ve ortalama 1,8 gram ağırlığında olan peletlerin kapsamının büyük çoğunluğunu \% 64,58 oran ile küçük memeli hayvan; diğer \% 32.42'lik kısmı ise kuş ve böcek kalıntıları oluşturmaktadır. Toplanan peletler içinde küçük kuş türlerine ait kalıntıların da yüksek oranda mevcut olduğu görülmüştür.

Otus brucei'nin tünediği ağaçlar altında toplanan 26 pelet içerisinde 31 memeli hayvan kalıntısı tanımlanmıştır. Genel olarak her pelette bir veya iki, sadece bir pelette de üç (ortalama 1,85 ) küçük memeli hayvan kalıntısına rastlanmıştır. Peletlerden on dört tanesinde bir; on tanesinde iki; bir tanesinde üç adet hayvan kalıntısı (1 adet Mus sp., 2 adet Cricetulus migratorius) bulunmuştur. İki memeli ordosundan beş türe (Soricomorpha (Böcekçil): Crocidura suaveolens, ve Rodentia (kemirgen) : Microtus guentheri, Mus sp., Meriones tristrami, Cricetulus migratorius) ait kalıntılar tespit edilmiştir (Tablo 1).

Memelilerin büyük kısmını, \% 87,09 oranı ile Rodentia türleri ve \% 12,9 oranında Soricomorpha ordosundan Crocidura suaveolens türü oluşturmaktadır. Rodentia türlerini oluşturan familyalar Cricetidae, Microtidae ve Muridae 'dir. Mus sp. ve Cricetulus migratorius türleri pelet kalıntıları içinde $\%$ 29,03 oranları ile eşit yoğunlukta bulunmuştur. Microtus guentheri \% 22,58 oran ile en çok rastlanan üçüncü türdür. Meriones tristrami türü ise \% 6,45 oranında tespit edilmiştir (Tablo 1).

Baykuş peletlerinin büyük kısmını genel olarak küçük memeli hayvanların kalıntıları meydana getirmektedir $[4,6,13,14,26]$. Bate [4] her pelette genel olarak bir veya iki ve bir pelette maksimum yedi küçük memeli hayvan kalıntısı tespit etmiştir. Diyarbakır'dan Asio otus peletlerinde, her pelette genel olarak bir veya iki; bir pelette maksimum dört memeli hayvan kalıntısı bulunmuştur [13-14]. Yine Diyarbakır'dan Tyto alba peletlerinde genel olarak 1-3 hayvan kalıntısı tespit edilmiş ve bir pelette maksimum yedi memeli hayvan kalıntısına rastlanmıştır [22]. Bu çalışmada ise Otus brucei'nin her pelette genel olarak 1-2 hayvan ( ortalama 1.85) kalıntısı tespit edilmiş ve bir pelette maksimum üç memeli hayvan kalıntısına rastlanmıştır.

Seçkin ve Coşkun [13-14] Asio otus peletlerinde 8 küçük memeli hayvan türü (Crocidura suaveolens, Microtus guentheri, Microtus sp., Cricetus cricetus, Nannospalax ehrenbergi, Mus musculus, Meriones tristrami ve Rattus rattus) tespit etmişler ve Microtus guentheri'nin en fazla orana (\%71,3) sahip olduğunu kaydetmişlerdir. Seçkin ve ark., [22] aynı alandan alınan Tyto alba peletlerinde ise Crocidura suaveolens, Microtus guentheri, Mus sp., Meriones tristrami, Rattus sp. kalıntıları bulunduğunu ve Mus sp. kalıntıları en yüksek oranda $(\% 71,7)$; Microtus guentheri türü ise $\% 7,5$ oranıyla çok daha az yoğunlukta olduğunu tespit etmişlerdir. Şanlıurfa-Birecik'ten alınan Otus brucei'nin pelet örneklerinde Mus sp. ve Cricetulus migratorius türlerinin en fazla yoğunluğa sahip olduğu ve küçük kuş mevcudiyetinin de önemsenecek miktarda olduğu görülmüştür.

Dov ve Kiat [36] İsrail'den Otus brucei peletleri içerisinde sadece genç bir Mus musculus memeli türü bulunduğunu, besinlerinin çoğunu böceklerin (çekirge, cırcır böcekleri, kın kanatlılar ve örümcekler) oluşturduğunu ifade etmişlerdir. Şanlıurfa- Birecik’te Mus sp. $\% 29.03$ oranı ile en yüksek oranda rastlanan türdür.

Selçuk ve ark. [20] Amasya'da Uzun kulaklı orman baykuşu, Asio otus'un besininin büyük çoğunluğunu Microtus'ların oluşturduğunu ifade etmişlerdir. Otus brucei peletler içinde Microtus guentheri $(\% 22,58)$ oranı ile en çok rastlanan üçüncü tür (Tablo 1) olduğu görülmektedir. 
Tablo 1. Şanlıurfa Birecik’ten toplanmış, Çizgili İshakkuşu (Otus brucei) peletlerinde belirlenen memeli türleri oranı (\%) ve literatürde yer alan diğer baykuş türleri ile karşılaştırılması. * Toplam pelet içerisindeki oranı

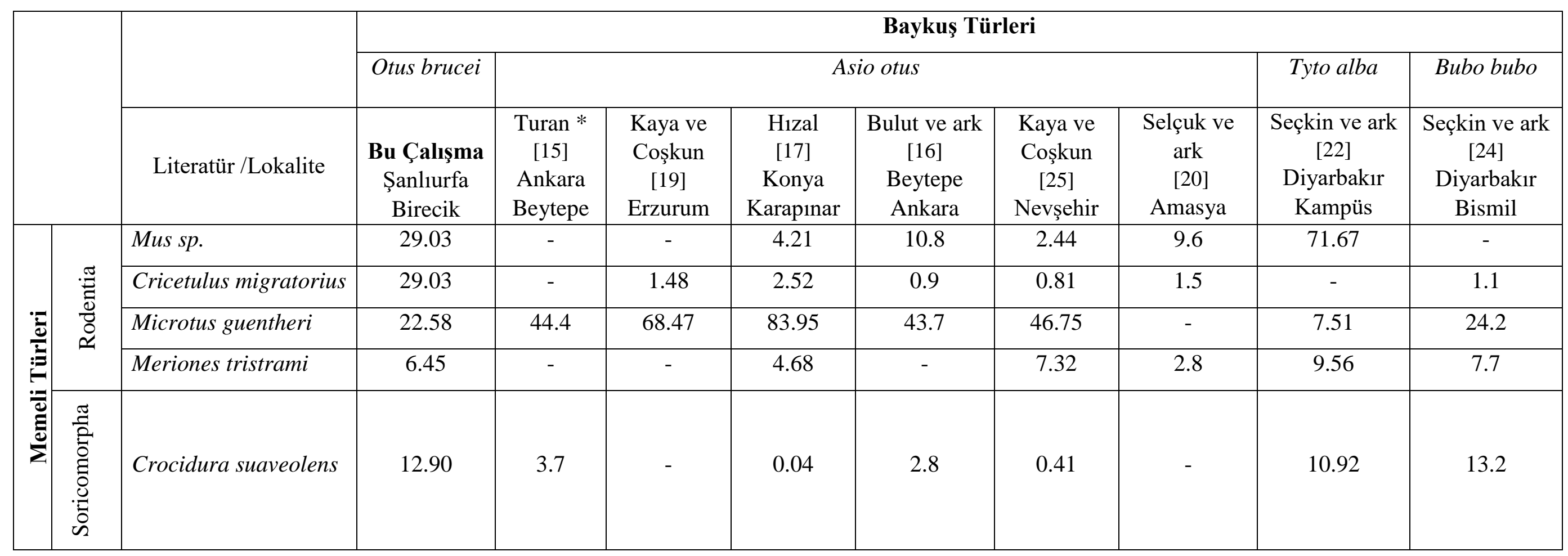




\section{Sonuç ve Öneriler}

Orta Anadolu'nun çeşitli bölgelerinde, Uzun Kulaklı Orman Baykuşu (Asio otus)'na ait pelet analizlerinde böcekçil memeli türü Crocidura suaveolens kalıntı oranlarının düşük olmasına karşlık, Güneydoğu Anadolu Bölgesin'de Tyto alba (Diyarbakır-Kampüs), Bubo bubo (Diyarbakır-Bismil) ve Otus brucei (Şanlıurfa-Birecik)'te yüksek oranda gözlenmesi bu türün Güneydoğu Anadolu'da bol bulunduğuna işaret etmektedir. Ayrıca bu türe Erzurum ve Amasya'da yapilan çalışmalarda rastlanmamıştır (Tablo 1).

Meriones tristrami 'nin pelet çalışması yapılan bütün bölgelerde çıkmış olması; Asio otus, Bubo bubo Tyto alba ve Otus brucei peletleri içerisinde yaklaşık eşit yoğunlukta ve düşük oranda bulunmasına rağmen bu türün Türkiye'nin bütün bölgelerinde bulunduğunu ve baykuşların temel besinleri arasında olduğunu göstermektedir.

Sonuç olarak, Şanlıurfa Birecik’te dağılış gösteren Otus brucei (Çizgili İshakkuşu) besinlerini çoğunlukla küçük memeli türleri oluşturmakta olup, peletleri içerisinde diğer baykuş türlerine nazaran daha az sayıda memeli kalıntısı bulunmaktadır. Cricetulus migratorius'un peletler içerisinde yüksek oranda çıkması bu türün Birecik’te yoğun olarak bulunduğunu göstermektedir.

Ülkemizde Otus brucei'nin beslenme alışkanlıkları üzerine yapılmış çalışma bulunmadığından bu baykuş türünün beslenme, üreme, koruma tedbirleri ve biyolojileri üzerine yapılacak çalışmalar yararlı olacaktır.

\section{Teşekkür}

Bu çalışma Dicle Üniversitesi Bilimsel Araştırma Projeleri Koordinatörlüğü tarafından desteklenmiştir (DÜAPK-05-FF-58 nolu Proje).

\section{Kaynaklar}

1. Heinzel H., Fitter R., Parslow J. 1995. Türkiye ve Avrupa'nın Kuşları. Türkiye Doğal Hayatı Koruma Derneği, 384s, İstanbul.

2. BirdLife International. 2016. Otus brucei. The IUCN Red List of Threatened Species 2016: e.T22688631A93203300. http://dx.doi.org/10.2305/IUCN.UK.2016-3.RLTS.T22688631 A93203300.en. (Erişim tarihi: 05.02. 2018).

3. Avibase- the world bird database. https://avibase.bsc-eoc.org/avibase.jsp. (Erişim tarihi:09. 02. 2018)

4. Bate D. M. A. 1945. Note on small mammals from the Lebanon Mountains, Syria. -Annals and Magazine of Natural History Serie, 11., xii: 141-158.

5. Obuch J., Benda P. 1996. Contribution to the feeding ecology of Strix aluco and Bubo bubo (Aves: Strigiformes) in southwestern Bulgaria. Acta Societas Zoologicae Bohemicae, 60: 43 - 49.

6. Amr Z. S., Al-Melhim W. N., Yousef A. 1997. Mammals remains from pellets of the Eagle owl, from Azraq Nature Reserve. Jordan. Zoology in the Middle East, 14: 5-10.

7. Obuch J.,Kristin A. 2004. Prey composition of the little owl Athena noctua in an arid zone (Egypt, Syria, Iran), Folia Zoologica, 53 (1): 65-79.

8. Kasparek M. 1985. Die Sultanssümpfe. Naturgeschichte eines Vogelparadieses in Anatolien. Heidelberg, 156s.

9. Kasparek M. 1988. Bafasee: Natur und Geschichte in der türkischgen Ägäis. Heidelberg, 176s. 
10. Kock D. 1990. Notes on mammals (Insectivora, Rodentia) taken by the Tawny Owl in NW Turkey. Zoology in the Middle East, 4: 5-9.

11. Nadachowski A., Smielowski, J., Rzebikkowalska, B., Daoud A. 1990. Mammals from the Near East in Polish collection. Acta Zoologica Cracoviensia, 33(6): 91-120.

12. Steiner H. M., Vauk G. 1966. Säugetiere aus dem Beyşehir-Gebiet (Konya, Kleinasien). Zoologische Anzeiger, 176: 97-102.

13. Seçkin S., Coşkun Y. 2005. Small mammals in the diet of the Long-eared Owl from Diyarbakır, Turkey. Zoology in the Middle East, 35: 102-103.

14. Seçkin S., Coşkun Y. 2006. Mammalian remains in the pellets of the Long-eared Owls in Diyarbakır province. Turkish Journal of Zoology 30: 271-278.

15. Turan, L., 2005. Winter Diet of a Long-Eared Owl Population in Ankara, Beytepe. Hacettepe Journal of Biology and Chemistry, Volume 34: 69-76.

16. Bulut Ş., Akbaba B., Ayaş Z. 2012. Analysis of mammal remains from owl pellets (Asio otus), in a suburban area in Beytepe, Ankara. Hacettepe Journal of Biology and Chemistry,40, 233-237.

17. Hizal E. 2013. Diet of the Long-eared Owl, Asio otus, in Central Anatolia (Aves: Strigidae). Zoology in the Middle East, 59: 118-122.

18. Göçer E. 2016. Diet of a nesting pair of Long-eared Owls, Asio otus, in an urban environment in southwestern Turkey (Aves: Strigidae). Zoology in the Middle East, 62: 1-4.

19. Kaya A., Coşkun Y. 2017. Erzurum'dan Toplanan Kulaklı Orman Baykuşu (Asio otus) Peletlerinde Memeli Hayvan Türleri. BEÜ Fen Bilimleri Dergisi, 6(1): 47-50.

20. Selçuk A.Y., Bankoğlu K., Kefelioğlu H. 2017. Comparison of Winter Diet of Long-eared Owls Asio otus (L., 1758) and Short-eared Owls Asio flammeus (Pontoppidan, 1763) (Aves: Strigidae) in Northern Turkey. Acta Zoologica Bulgarica, 69 (3): 345-348.

21. Hoppe N. 1986. Pellet contents of the Barn Owl, near Samandağ, Turkey. Zoology in the Middle East, 1: 29-31.

22. Seçkin S., Coşkun Y., Yürümez G. 2006. Diyarbakır çevresindeki peçeli baykuş (Tyto alba) peletlerindeki memeli hayvan kalıntılarının dağılımı. 18. Ulusal Biyoloji Kongresi, pp 300, 26-30 Haziran, Kuşadası/Aydın.

23. Morgan D. 1983. An analysis of some Eagle Owl pellets from Turkey. Sandgrouse, 5: 105-106.

24. Seçkin S., Kaya A., Coşkun Y. 2012. Başaklı Köyü (Diyarbakır-Bismil) Civarında Yaşayan Puhu (Bubo bubo)'ların Peletlerindeki Küçük Memelilerin Dağılımı. Cumhuriyet Üniv. Fen Bilimleri Dergisi, Vol. 33 (1): 34-42.

25. Kaya A., Coşkun Y. 2014. Nevşehir'de Baykuş Peletlerindeki Memeli Hayvan Kalıntılarının Dağılımı. Nevşehir Bilim ve Teknoloji Dergisi, 3 (1): 39-44.

26. Obuch J. 2001. Dormice in the diet of owls in the Middle East. Trakya University Journal of Scientific Research, Ser. B, 2:145-150.

27. Ellerman J. R. 1940. Key to the Rodents of South West Asia. Proceedings of the Zoological Society of London, 118: 785-792.

28. Ellerman J. R. 1941. The families and genera of living rodents. Vol. 2. Family: Muridae. British Museum Natural History, 690s, London.

29. Ognev S.I. 1947. Mammals of the USSR and adjacent countries, Rodents. Vol.5. 809s. IPST, Jerusalem.

30. Osborn D. J. 1962. Microtinae from Turkey. Rodents of the subfamily Microtinae from Turkey, Journal Mammalogy, 43: 515-529. 
31. Vinogradov B.S., Argiropulo A.I. 1968. Fauna of the USSR. Mammals. "Key to rodents" Zoological Institute of the Academy of Science of the U.S.S.R. New series No: 29, IPST, 1968 241s, Jerusalem.

32. Osborn D. J.,Helmy I. 1980. Fieldiana Zoology - The Contemporary Land Mammals of Egypt (Including Sinai). Field Museum of Natural History: 253 - 273 pp.

33. Corbet G. B., 1978. The Mammals of the Palaearctic Region, A Taxonomic Review, British Museum (Natural History) Cornel University Press, London and Ithaca.

34. Kryštüfek B., Vohralik V., 2001. Mammals of Turkey and Cyprus. Order Insectivora (Introduction, Checklist, Insectivora). Knjiznica Annales Majora, 141 p. Llubliana.

35. Kryštüfek B., Vohralik V. 2009. Mammals of Turkey and Cyprus. Rodentia II: Cricetinae, Muridae, Spalacidae, Calomyscidae, Capromyidae, Hystricidae, Castoridae. Knjižnica Annales Majora, Koper 140s.

36. Dov A.B., Kiat Y. 2016. Breeding Pallid Scops Owls in Rift valley, Israel, in spring 2015. Dutch Birding 38: 146-158, 